\title{
An e-Health System for the Elderly (Butler Project): A Pilot Study on Acceptance and Satisfaction
}

\author{
Cristina Botella, Ph.D., ${ }^{1,2}$ Ernestina Etchemendy, B.A., ${ }^{2}$ Diana Castilla, B.A., ${ }^{1-4}$ \\ Rosa María Baños, Ph.D., ${ }^{2-4}$ Azucena García-Palacios, Ph.D., ${ }^{1-4}$ Soledad Quero, Ph.D., ${ }^{1-4}$ \\ Mariano Alcañiz, Ph.D., ${ }^{2,4}$ and José Antonio Lozano, Ph.D. 2,4
}

\begin{abstract}
The Butler Project is a technological e-health platform that uses the Internet to connect various users; it was designed to deliver health care to the elderly. The Butler platform has three levels of implementation: diagnosis (mood monitoring, alert system, management reports), therapy (training in inducing positive moods, memory work), and entertainment (e-mail, chat, video, photo albums, music, friend forums, accessibility to the Internet). The objective of this work is to describe the psychological aspects of the platform and to present data obtained from four users. Results show that after using the system, the participants increased their positive emotions and decreased their negative ones; in addition, they obtained high levels of satisfaction and experienced little difficulty in using the system.
\end{abstract}

\section{Introduction}

A N INCREASE IN LIFE EXPECTANCY and a decrease in birth rates are resulting in an increasingly aging population, especially in those countries that are part of the so-called "first world." In 2000, 6.9\% of the world's population (421 million) were 65 years old or more, and estimates indicate that by 2050 , this percentage will be $16.1 \%$ (1465 million) ${ }^{1}$ This demographic transition is changing the concept of old age; no longer is it characterized by retirement, illness, inactivity, or isolation; rather, it is increasingly considered merely a further step in the life cycle, with its own characteristics and variations. Researchers are paying increasing attention to how manipulation of environments and lifestyles can influence how we age. Another consequence of the new demographic distribution is an overload on the health care system. According to The State of Aging and Health, ${ }^{2}$ psychological problems in the elderly are poised to become a major public health issue because they will involve an increase in the demand for and costs of health services. Regarding the morbid characteristics of the elderly population, several studies indicate the importance of symptoms and depressive disorders. For example, Yaffe et al. ${ }^{3}$ found that depressive symptoms in older people are associated with poor cognitive function and greater cognitive decline. Katon et al. ${ }^{4}$ also indicated that the presence of depressive symptoms in the elderly correlates with a significant increase in health care demands, compared with people without depressive problems. In a similar vein, Ganguli et $\mathrm{al}^{5}$ found that depression was one of the best predictors of mortality in the elderly population. Evidently, when depression is undetected or inadequately treated, it has serious consequences, which could even be fatal.

Significantly, this population shift coincides with the technological revolution of the 21st century, which is redefining how people communicate with and relate to each other. Information and communication technologies (ICTs) increase the speed of everyday life while helping satisfy myriad demands; while this is very rewarding to those who enjoy the benefits of ICTs, it also segregates and excludes those who cannot understand the rules of this "new world." Social interactions are increasingly channeled through ICTs, and those who have not mastered this new language cannot participate. Of course, elderly people learned to interact in a completely different reality. This generational gap, compounded by the expected changes of this phase of life (physical changes, loneliness, loss of friends and family, social displacement), exacerbates loneliness, depressive symptoms, anxiety, and adaptive disorders.

Fortunately, the development of ICTs is also helping to solve some of the previously mentioned difficulties in the health field. There are already several works that suggest the potential of ICTs to improve the quality of life of elderly

\footnotetext{
${ }^{1}$ University Jaume I, Castellón, Spain.

${ }^{2}$ Ciber. Fisiopatología Obesidad y Nutrición, Instituto de Salud Carlos III, Spain.

${ }^{3}$ University de Valencia, Valencia, Spain.

${ }^{4}$ University Politécnica de Valencia, Valencia, Spain.
} 
people. For example, McConatha et al. $^{6}$ found that the use of an interactive computer program among elderly people had an impact on the daily routine of its users and produced cognitive improvement. Likewise, Plude and Schwartz ${ }^{7}$ demonstrated the effectiveness of interactive CDs for memory training in older people. Furthermore, Franco et al. ${ }^{8}$ developed and successfully implemented a computer system called GRADIOR for neurocognitive assessment and rehabilitation. Other studies ${ }^{9}$ also suggest the effectiveness of ICTs for monitoring physical and cognitive capacities of elderly people, as well as the positive impact they have on emotional, social, physical, and environmental care institutions.

Regarding the areas of social skills and communication, Emering et al. ${ }^{10}$ used new technologies to facilitate communication among the elderly and to reduce the feelings of loneliness and isolation that often arise in this population. Wright ${ }^{11}$ noted that older people who used the Internet as a social support network established friendly relations in addition to supportive relationships. Cody's group ${ }^{12}$ trained older populations to utilize the Internet and noted that those who completed the training program gained the necessary skills to navigate the Internet, to achieve high levels of social connectivity, and to establish high levels of social support and more positive attitudes toward the Internet. Another project, ACTION, ${ }^{13}$ is based on a videoconferencing system via Internet and is aimed at improving quality of life, increasing independence, and decreasing feelings of social isolation in elderly people and their caregivers; data indicate that $88 \%$ of users experienced decreased isolation and loneliness. Similarly, the CIRCA ${ }^{14}$ project is designed to promote communication among elderly people with dementia using pictures, videos, songs, music, and encouraging interaction via a touch screen.

A project developed by Mynatt et al. ${ }^{15}$ called Digital Family Portrait consists of a portrait similar to a traditional one, except that the images in it change daily, displaying various scenes captured from daily life; one portrait is installed at the elderly person's house and another at a relative's house. The Nostalgia system ${ }^{16}$ allows its users to listen to old news and 20th-century music. Tse et al. ${ }^{17}$ conducted a study in which they describe the development, implementation, and evaluation of an e-health program for elderly people, the results of which showed a significant increase in users' computer skills; it enabled them to access information via the Internet and expand their knowledge in the field of health. They evaluated the learning experience very positively. Finally, Roger and Fisk $^{18}$ developed a computer program aimed at helping elderly people with their housework.

As shown by these projects, there is always a clear intention to improve the quality of life of elderly people. This goal is also present in the Butler system. However, this tool aims to improve upon the performance of previous systems.

Butler has an application specifically targeted to the elderly and includes a range of recreational and therapeutic activities tailored to the specific needs of this population. It was designed to exercise key components for optimal aging, such as integration, communication, learning, socioemotional networks, and training in positive emotions (the last being the most crucial for the mental health of elderly people ${ }^{19}$ ). In addition, Butler is optimized for health professionals; it includes tools for optimizing evaluation, generates protective measures for a healthy lifestyle, and provides therapeutic tools that can be used inside and outside of the therapeutic physical context, thereby extending its applicability effectiveness.

This work has two objectives: to offer an overview of the system, including the tools it offers, and to present preliminary data on the satisfaction of four users obtained in a pilot study of their initial interaction with Butler.

\section{Program Description}

Butler is divided into three platforms (user, professional, external), each of which includes different resources in each of the three levels of implementation (diagnostic application, therapeutic application, playful application). The system features collaborative multimedia technology with the Internet as a network linking different categories of users (user, professional, external).

\section{User platform}

The user indicates the elderly person. The user community is designed to be established by elderly people who use the application from their homes, a friend or family member's house, or even from different nursing homes. The aim of the user platform is to provide diagnostic, therapeutic, and playful support.

\section{Professional user platform}

Professional users are the health agents who are part of the Butler network and have clinical responsibility for the users. Their levels of intervention are diagnostic and therapeutic, and the platform is designed to facilitate and optimize their work. In this platform, the professionals can access the diagnosis and history of each participant for whom they are responsible. Butler thereby allows the practitioner to maintain a database on all of the users' daily emotional information. It also includes an alarm system, which sends a warning to the professional in charge when the user's score has reached a certain clinical level and restricts the user's access to tools to only those which are therapeutically appropriate to the situation.

\section{External user platform}

External user are the people who make up the external socioemotional network of the user, such as family and friends. This platform operates only at a playful level and allows the elderly to share books of their lives, favorite pictures, and memories and to write e-mails, chat, or videoconference with their contacts.

The three applications included in Butler (diagnostic, therapeutic, playful), along with the various tools offered in each one, are described.

Diagnostic application. The aim of this application is to detect symptoms of anxiety and depression in users. It includes a decision algorithm that allows Butler to react in real time to the user's clinical needs. To do this, an evaluation using widely used and validated psychological scales is performed when the user accesses the system. If the clinical status of the person is within the normal range, Butler offers its full potential. In the case that any change in mood (anxiety or depression) is detected, the system performs a more detailed exploration; depending on the result, it offers the most 
appropriate options for the user's emotional state and sends the appropriate warning to the professional user platform. This application also summarizes the information so the professional can process it efficiently through period analyses, data tables, bar graphics, and more.

Clinical and therapeutic application. The therapeutic strategies of Butler have previously demonstrated their usefulness. $^{20,21}$ Specifically, Butler offers two therapeutic elements:

1. Virtual worlds to generate positive emotions. This tool includes two 3D virtual environments that present visual and auditory stimuli to produce changes in users' moods (one for joy and one for relaxation). These environments include several procedures for mood induction often used in psychology (narrative, autobiographical memories, relaxation procedures). From the professional platform, the $3 \mathrm{D}$ environments the user has visited and how long he or she remained in each are monitored.

2. Therapeutic Book of Life (TBL). This tool, based on the Review of Life, ${ }^{22,23}$ allows practitioners to apply a training program based on autobiographical memory. TBL is used jointly by the therapist and the user and is active in the professional platform when the diagnostic application detects significant levels of discomfort in the user. The TBL comprises questions and images that correspond to different stages of the elderly person's life and are intended to evoke specific positive memories from each period. The professional records various memories that the user generates in each therapy session. The elements already covered in therapy can be made available to the user later if the professional believes it is desirable. This helps to increase the power of the professional work and hence the therapeutic efficacy.

Playful application. The following tools and services are available through Butler's playful application.

1. Book of Life. This tool functions like a diary in which the users can write as many pages as they wish and introduce multimedia elements. In addition, they can decide which pages of the book can be read by other people and which are private (only their author can access them). The tool is designed to improve communication and increase the number of the elderly person's social relationships by allowing him or her to share vital memories with other users, relatives, and friends.

2. Communication tools. These tools enable the user to more easily communicate with relatives, friends, and other Butler network users and to send e-mails or, initiate videoconferences. They are designed to be very simple to help the older person maintain existing relationships with family and friends and to encourage new relationships with other system users.

3. Make friends. This tool facilitates and promotes the formation of a virtual community of friends, with the aim of expanding the network of support for the elderly. In order to build a network of friends, the system displays a photo and a brief profile of each user in a virtual space. The users can choose to send invitations to form relationships, share their Book of Life, and be part of the contact system.

4. My Memories. Butler gives users a space where, with assistance, they can store as many photos and music files as they please. Everything that users include in this section can be accessed at any time for their Book of Life or for e-mails sent via Butler.

5. Navigating the Internet. Access to the network has been adapted so users can easily access a search Web page. They can learn to look over their areas of interest, and there is always an option on the screen to return to the Butler start menu system.

\section{Using the System}

\section{Participants}

The participants were four elderly women, 66, 67, 73, and 74 years old, all of whom attend a special university program for elderly people at Jaume I University and at University of Valencia (Spain). All agreed to voluntarily participate in the investigation. As this is the first study of Butler, and following the necessary ethical precautions, we confirmed that the participants did not have psychological or cognitive problems nor exhibit high scores in anxiety or depression. A more detailed description of participants is presented in the Results section.

\section{Measures}

The following instruments were used to assess the emotional aspect and satisfaction with the system:

Visual Analogic scale (VAS). In this instrument, the person quantitatively assessed (from 1, not at all, to 7, totally) the degree to which he or she experienced different emotions at various periods. A variant of the Gross and Levenson ${ }^{24}$ measure was used. The emotions we assessed were joy, sadness, anxiety, and relaxation. This scale was applied before and after each Butler session.

Satisfaction state (SST). Users evaluated their degree of satisfaction with what they experienced in each Butler session, using an adaptation of a visual analog scale consisting of seven facial expressions, from 0 (maximum dissatisfaction face) to 6 (maximum satisfaction face).

Difficulty of use. Participants assessed the difficulty of using the system on a scale from 1 , very easy, to 5 , very difficult.

Time perception. This parameter is related to the level of difficulty of the $\operatorname{task}^{25}$ and can be considered an indirect measure of the level of absorption experienced by the user. Absorption is the ability to "get lost" in the task at hand, to become fully involved in a perceptual or ideational imaginative experience. ${ }^{26}$ Participants were asked to estimate the time they thought they had been using the system. Afterwards, the real time was recorded in order to calculate the difference.

\section{Procedure}

Butler has been previously tested for usability. ${ }^{27}$ After correcting the problems encountered in these assessments, 
we obtained the first definitive version of the system: Butler 1.0, which was used to conduct the present study. First, we contacted people over 60 years old who attended special courses at Jaume I University and University of Valencia and invited them to participate in the study. Once the users voluntarily agreed to participate, they were given the state version of the State-Trait Anxiety Inventory Scale (STAI-S) ${ }^{28}$ and the Yesavage 15-item short version of the Geriatric Depression scale $\mathrm{e}^{29}$ in order to detect clinical scores for anxiety and depression (which were set as exclusionary criteria). Once the informed consent was signed, the participants were given the key to access the system, and they came to the university to use Butler once a week, in the times of their own choosing. Before each session, a researcher administered the $\mathrm{VAS}^{24}$ and after each session, the user completed all the measures described previously. Users also decided which activities to perform at each session. The researcher was located in an adjacent room in order to be available for any questions that arose, although users were encouraged to follow the instructions that Butler gave them at every step.

\section{Results}

The first result to emphasize is that none of the participants abandoned the study, and all of them participants came back to use Butler system. They expressed satisfaction with all of their sessions and wanted to return the next week. The number of sessions and the activities that the users did in each of them are show in Table 1.

U1 (user 1) was a 73-year-old female, who was widowed and lived alone, had a medium educational level, and had no degree of experience with computers or mobile phones. After using Butler (see Fig. 1), her level of happiness increased and did not change when it was previously high. A decline in levels of sadness was also observed. Her anxiety levels were always very low. As for relaxation, her levels increased in all sessions, except for the last one in which she exhibited notable excitement and joy and remained the longest with the system (see Fig. 1) when she learned some of the possibilities offered by the Internet. In her first session, she wrote an e-mail to her grandson and enclosed a family photo she using the My Memories section. She was emotional when she read her grandson's reply the following week. The activity she liked most was surfing the Internet. She likes history, so when she discovered that the Internet has plenty of material on this topic, she felt great joy; moreover, she expressed the intention to buy a computer so she could use Butler at home. Her satisfaction level with the system increased through the sessions, reaching the highest level at the last two visits. Regarding difficulty of use, she always valuated Butler as quite easy, and her subjective evaluation of time was lower than the real time passed at all sessions. See Figure 2.

U2 was a 74-year-old female who was widowed and lived alone, had a medium educational level, and had no degree of experience with computers, although used a mobile phone. Similar results to those of the previous participant (see Fig. 1) were observed: an increase in joy and relaxation or maintenance when the levels were already high before the session and a decrease in sadness. Her anxiety levels were always low. She particularly enjoyed the third session when she found on the Internet a picture of a church she attended when she was young and asked to save those pictures in My
Memories with a melody that made her remember beautiful moments with her husband. Her level of satisfaction increased over the sessions, her level of difficulty ranged between normal and quite easy, and like U1, her subjective perception of time was always less than the real time. See Figure 2.

U3, a 67-year-old female, was widowed and lived alone, had a primary level of education, and used the computer only to send e-mails. Again, the system produced similar effects (see Fig. 1) in joy, sadness, and relaxation levels. As for anxiety, U3 showed a decreased in her anxiety levels. What she liked most was the Nature Walk and exploring the Internet. She appreciated most that the system did not frightened her as other computers did: it gave her more confidence, and she was encouraged to learn more and enjoy it. Her satisfaction levels were around maximum in most of the sessions, and she consistently valuated Butler as quite easy (except for sessions 3 and 4). Her subjective evaluation of the time was always less than the real time, except for sessions 1 and 4 . See Figure 2.

U4, a 66-year-old female, was married, had an advanced education, and had no experience with computers. At the beginning of the experience, she was discouraged because her son-in-law had died recently. She did not believe that she would like the Nature Walk. However, this became her favorite application, and she said that she now appreciated and enjoyed real landscapes more than she had previously. Like the previous users, $\mathrm{U} 4$ experienced positive changes in all the emotions in all sessions except for the last one, which coincided with an unfavorable medical diagnosis on the previous day. U4 reported that although she knew that Butler was not going to resolve her health problem, using it did help her to feel a little bit better. In the last session, she felt very happy because her daughter (who lives far away) wrote her an e-mail using Butler (see Fig. 1). Regarding difficulty level, she assessed Butler as strongly easy even when she used a great number of tools (see Fig. 2 and Table 1), and her subjective evaluation of the time (see Fig. 2) was always less than the real time in all sessions.

\section{Discussion}

Due to the complexity of Butler, the first objective of this study was to present an overview of its features. As previously mentioned, our societal challenge is to create a clinical and health system that can accommodate a growing population of elderly, incorporating primary levels of intervention that can reduce costs and facilitate healthy lifestyles. Previous work in this area indicates that the use of several tools derived from ICTs by elderly people had a positive impact on their communication, social connectivity, and affective, physical, and emotional areas. ${ }^{09,11,14,16}$ However, each of these studies focused on a single technological resource (videoconferencing, listening to music, or learning to navigate the Internet). Butler follows this same strategy but incorporates several tools in a single application. In addition, Butler was designed for two levels of use: one for clinical health professionals and the other for the general elderly population. For the clinical health professionals, Butler offers a diagnostic tool for managing primary health interventions, while keeping the professional informed of the status of large numbers of patients with a level of detail and speed far more complex than other current programs. This enables much more effective and 


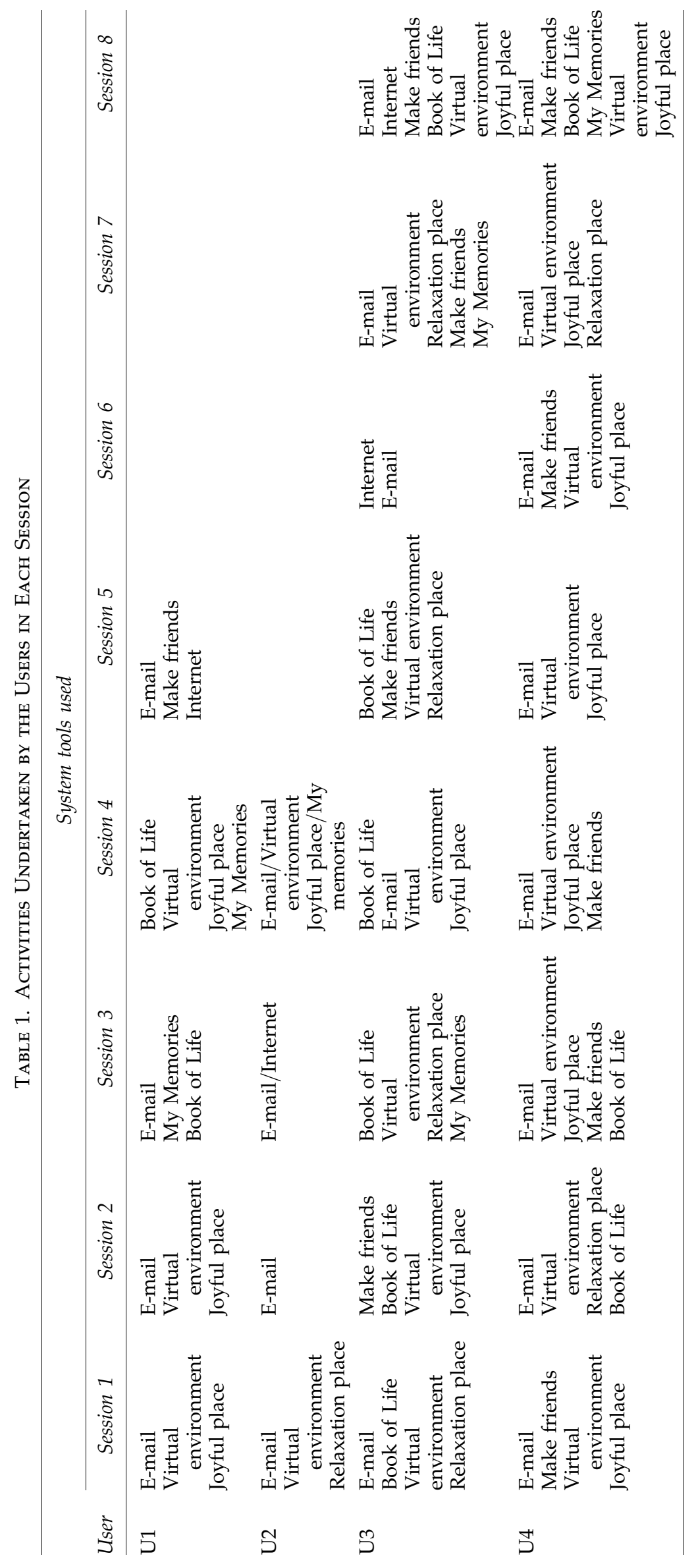




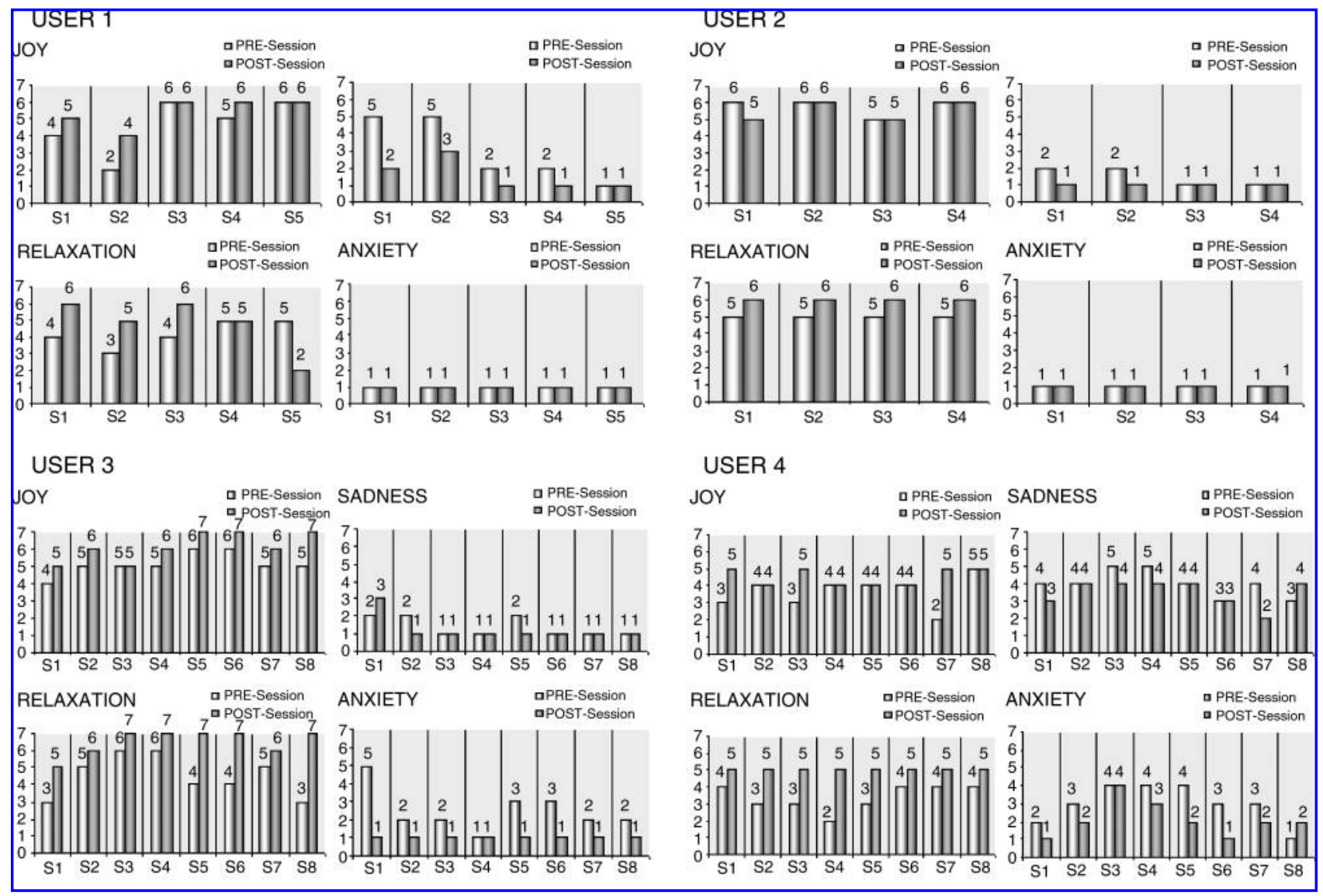

FIG. 1. Visual Analogic Scale.

rapid application of the program, which not only reduces health care costs but also assists health professionals who work with this population. Significantly, several studies ${ }^{30,31}$ indicate that work teams in geriatric centers are at risk for burnout because of the constant physical and emotional stress that their work entails. The consequence for those who suffer thusly is a reduced quality of life; this then affects people under their care, who suffer from the emotional detachment, emotional and physical exhaustion, and irritability of the health care provider. Combining the risk factor of being a health professional in the geriatric field with the current and future population distribution, it is increasingly important to learn to cope adequately with the needs of both the health professional and the elderly population. Butler is specifically adapted for the needs of the elderly population and is designed to promote health, satisfaction, and personal wellbeing by presenting a series of strategies including exercising emotional capabilities, learning new communication skills and ways of engaging friendships, increasing social support networks, strengthening the desire to keep learning new activities, and encouraging curiosity, satisfaction, and surprise at developing new skills. However, a limitation that the platform could have is the restriction of the number of participants in the Butler network. One possible solution could be to integrate the Butler platform with other existing social networks or to teach the professional users about these other online groups in order for them to have access to these from the Butler system with a simple click on their link.
The second objective of this study was to present the first data from a pilot study. This study focused on only one aspect of the system, the playful application, limiting the type of user to people without clinical anxiety and depression and without mental or physical problems. It may be premature to draw general conclusions from these preliminary data from a limited number of cases; however, the early results are encouraging. As noted in the results, the use of Butler generated an increase in positive emotions, a decrease in negative ones, high levels of satisfaction, low levels of difficulty, and a perception of session duration that was less than the actual time in people who were not familiar with the use of ICTs. This initial pilot study indicates that it is possible to reduce the gap between the elderly and computers; it was beneficial to the elderly to join these two worlds. The fact that the users came week after week, maintaining their interest and motivation, was very encouraging. However, we will have to wait to discover what happens in the case of a clinical population who may be located in nursing homes and whose physical or mental condition may be impaired.

Our next steps are to conduct studies on Butler validity and effectiveness in the clinical and subclinical elderly populations and to observe the effects of each of the system's tools. We will also study how the professional user platform works, its effects on workers, its interaction with the user's platform, and its influences on therapeutic outcomes. Next, we must investigate the effects of the external user platform on 


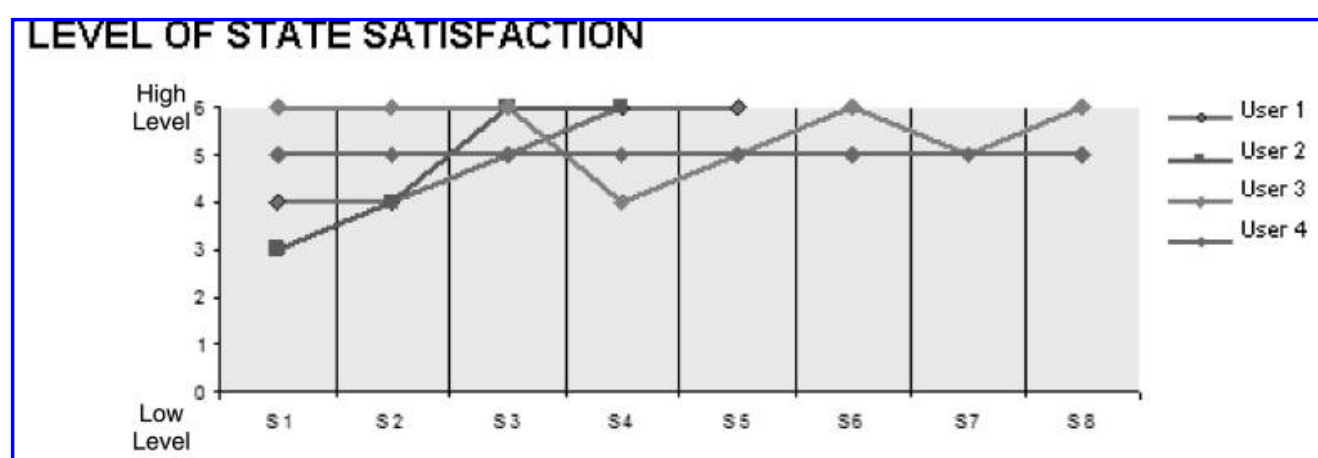

DIFFICULT

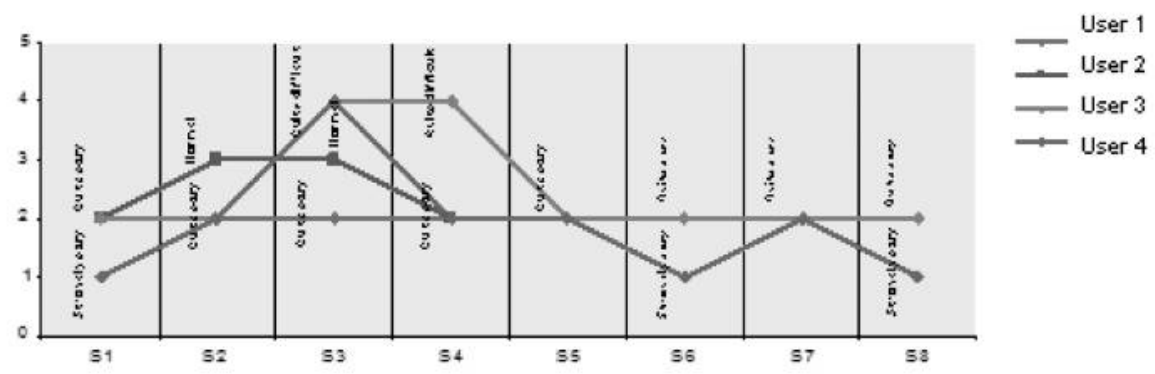

\section{USERS' SUBJECTIVE TIME}

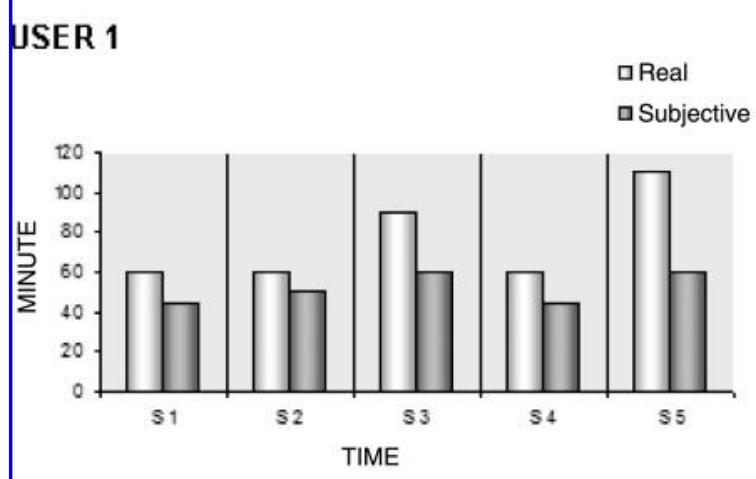

USER 2

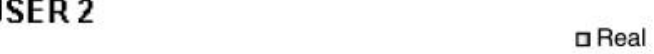

\section{USER 3}
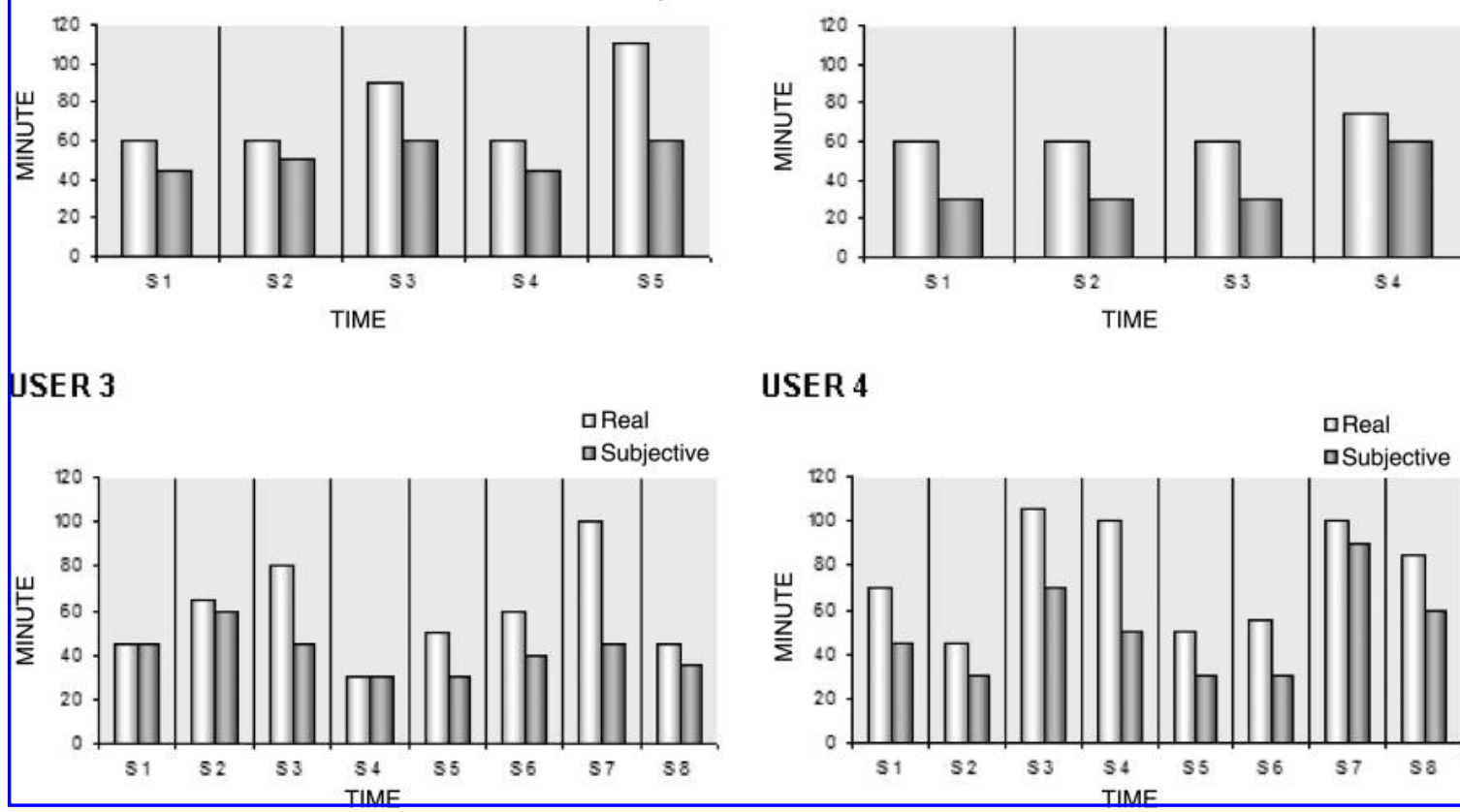

USER 4

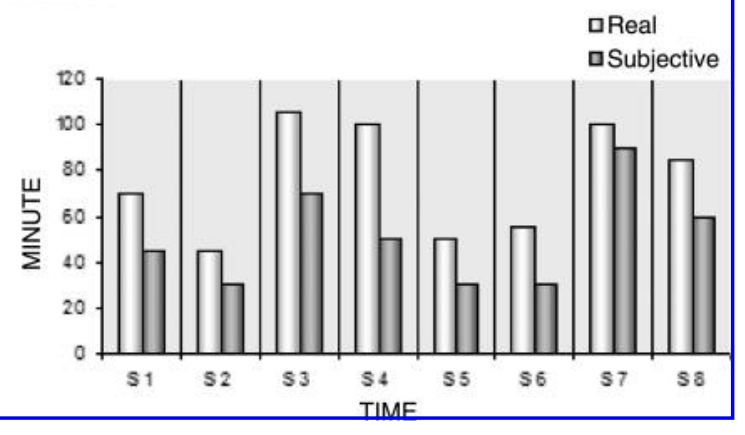

FIG. 2. Level of satisfaction, difficulty and user's subjective time in each session.

elderly people in regard to their social connectivity, network support, mood, and quality of life. Finally, we will analyze the impact that the system can have from a family perspective, including the reactions of family members to receiving emails or having videoconferences with their elders who were previously not connected to the computing world. It is evident that a technological system like Butler requires further study. We are committed to furthering its effectiveness in real applications.

\section{Acknowledgment}

This study was funded in part by Ministerio de Educación y Ciencia Spain, Proyectos Consolider-C (SEJ2006-14301/ 
PSIC), "CIBER of Physiopathology of Obesity and Nutrition, an initiative of ISCIII," by Programa de Acciones Integradas con Sudáfrica (HS2006-0001), and by the Generalitat Valenciana. Prometeo Program.

\section{Disclosure Statement}

No competing financial interests exist.

\section{References}

1. Secretaría de Estado de Política Social IMSERSO Las personas mayores en España Informe 2006. www.imsersomayores.csic.es/documentos/estadisticas/informe-mayores/ 2006/volumen-1/02-informe2006-vol1-cap1.pdf (accessed Sept. 30, 2008).

2. Merck Institute of Aging \& Health. (2004) The state of aging and health in America 2004. www.agingsociety.org/ agingsociety/pdf/SAHA_2004.pdf (accessed Sept. 30, 2008).

3. Yaffe K, Blackwell T, Gore R, et al. Depressive symptoms and cognitive decline in nondemented elderly women: a prospective study. Archives of General Psychiatry 1999; 56:425-30.

4. Katon WJ, Lin E, Russo J, et al. Increased medical costs of a population-based sample of depressed elderly patients. Archives of General Psychiatry 2003; 60:897-90.

5. Ganguli M, Dodge HH, Mulsant BH. Rates and predictors of mortality in an aging, rural, community-based cohort: the role of depression. Archives of General Psychiatry 2002; 59:1046-52.

6. McConatha D, McConatha JT, Dermigny R. The use of interactive computer services to enhance the quality of life for long-term care residents. Gerontologist 1995; 34:553-6.

7. Plude DJ, Schwartz LK. The promise of compact discinteractive memory training with the older people. Educational Gerontology 1996; 22:507-21.

8. Franco MA, Orihuela T, Bueno Y, et al. (2002) Programa GRADIOR: programa de evaluación y rehabilitación neurocognitiva por ordenador [Gradior Program: Computer program for evaluation and cognitive rehabilitation]. Valladolid, Spain: Ed. EdIntras.

9. Caoutte A, Vincent C, Montreuli B. Use of telemonitoring by elders at home: actual practice and potential. Canadian Journal of Occupational Therapy 2007; 74:382-92.

10. Emering L, Boulic R, Thalmann D. Conferring human action recognition skills to life-like agents. Applied Artificial Intelligence1999; 13:539-65.

11. Wright K. Computer-mediated social support, older adults, and coping. Journal of Communication 2000; 100-18.

12. Cody MJ, Dunn D, Hoppin S, et al. Silver surfers: training and evaluating Internet use among older adult learners. Communication Education 1999; 48:269-86.

13. Savolainen L, Hanson E, Magnusson L, et al. An Internetbased videoconferencing system for supporting frail elderly people and their carers. Journal of Telemedicine \& Telecare 2008; 14:79-82.

14. Gowans G, Campbell J, Alm N, et al. (2004) Designing a multimedia conversation aid for reminiscence therapy in dementia care environments. In CHI '04 extended abstract on human factors in computing systems, Vienna: ACM Press, pp. 825-36.

15. Mynatt ED, Rowan J, Craighill S, et al. (2001) Digital family portraits: providing peace of mind for extended family members. Proceedings of the ACM Conference on Human Factors in Computing Systems (CHI 2001). Seattle: ACM Press, pp. 333-40.

16. Nilsson M, Johansson S, Hakansson M. (2003) Nostalgia: an evocative tangible interface for elderly users. Proceedings of CHI 2003. Ft. Lauderdale, FL: ACM Press, pp. 964-5.

17. Tse MM, Choi KC, Leung RS. E-health for older people: the use of technology in health promotion. Cyberpsychology \& Behavior 2008; 11:475-9.

18. $\overline{\text { Roger W}}$, Fisk A. Cognitive support for elders through technology. Generation 2006; 30:38-43.

19. Avia MD, Vázquez C. (1998) Optimismo inteligente. Madrid: Impreso en Anzos S.L-Fuenlabrada.

20. Baños RM, Liaño V, Botella $C$, et al. (2006) Changing induced moods via virtual reality. In Ijsselsteijn WA, de Kort Y, Midden C, et al., eds. Persuasive technology: lecture notes in computer science. Berlin: Springer-Verlag.

21. Serrano JP, Latorre JM, Montañez J, et al. Life review therapy using autobiographical retrieval practice for older adults with depressive symptomatology. Psychology \& Aging 2004; 19:272-7.

22. Butler RN. Successful aging and the role of life review. Journal of the American Geriatrics Society 1974; 22:29-35.

23. Haight BK, Webster JD, eds. (1995) The art and science of reminiscing: theory, research method, and applications. Bristol, PA: Taylor \& Francis.

24. Gross JJ, Levenson RW. Emotion elicitation using films. Cognition \& Emotion 1995; 9:87-108.

25. Czerwinski M, Horvitz E, Cutrell E. Subjective duration assessment: an implicit probe for software usability. Proceedings of IHM-HCI 2001. Lille, France.

26. Tellengen A, Atkinson G. Openness to absorbing and selfaltering experiences ("absorption"), a trait related to hypnotic susceptibility. Journal of Abnormal Psychology 1974; 83:268-77.

27. Castilla DV, Botella C, Baños RM, et al. Usability design and evaluation process of a multitask system for psychological teleassistance in elders: The Butler project. (in press.)

28. Spielberger CD, Gorsuch RL, Lushene RE. (1970) STAI, Manual for the State-Trait Anxiety Inventory. California: Consulting Psychologist Press (translated into Spanish by Seisdedos N, 1982; published by TEA Ediciones, 1982).

29. Sheikh JI, Yesavage JA. (1986) Geriatric Depression Scale (GDS): recent evidence and development of a shorter version. In Brink TL, ed. Clinical gerontology: a guide to assessment and intervention. New York: Haworth Press, pp. 165.

30. Gandoy-Greco M, Clemente M, Mayán-Santos JM, et al. Personal determinants of burnout in nursing staff at geriatric centres. Archives of Gerontology \& Geriatrics 2008; 1833:1-4.

31. Olabarría B, Mansilla F. Ante el burnout: cuidados a los equipos de salud mental [Faced with burnout: Caring for mental health teams]. Revista de Psicopatología y Psicología Clínica 2007; 12:1-14.

Address reprint requests to: Dr. Cristina Botella

Departamento de Psicología Básica, Clínica y Psicobiología Facultad de Ciencias Humanas y Sociales Avda. Vicente Sos Baynat s/n 12071 - Castellón Spain

E-mail: botella@psb.uji.es 